\title{
Deteksi Validitas Berita pada Media Sosial Twitter dengan Algoritma Naive Bayes
}

\author{
Esther Irawati Setiawan, Teknik Informatika, Institut Sains dan Teknologi Terpadu Surabaya, \\ Sugiharto Johanes, Teknik Informatika, Institut Sains dan Teknologi Terpadu Surabaya, \\ Arya Tandy Hermawan, Teknik Informatika, Institut Sains dan Teknologi Terpadu Surabaya, \\ Yuni Yamasari, Teknik Informatika, Universitas Negeri Surabaya.
}

\begin{abstract}
Abstrak - Banyaknya berita-berita online sering menarik minat masyarakat untuk membacanya, tetapi kadang dengan terlalu banyaknya berita tersebut membuat orang susah mendapatkan informasi yang terpercaya. Berita palsu merupakan kumpulan kata atau kalimat yang mengandung informasi yang tidak benar yang berupaya untuk membohongi atau mengarahkan pembaca atau pendengarnya agar mendukung atau percaya dengan isi beritanya. Penyebar berita palsu umumnya mengetahui bahwa berita yang disebarkan tidak benar. Tujuan penelitian ini adalah mendeteksi berita palsu yang tersebar pada media sosial. Dalam mengklasifikasi berita palsu, deteksi validitas berita digunakan algoritma naïve bayes sebagai kategorisasi teks berbasis pembelajaran mesin. Penelitian ini juga membangun website yang menyediakan fitur web service, pencarian berita yang ada di Twitter, dan klasifikasi berita secara manual. User interface merupakan website berbasis PHP dimana pengguna dapat melakukan interaksi secara langsung sepeti komentar, login, atau melihat artikel-artikel yang sudah diklasifikasi. Sedangkan back-end dari website ini adalah program klasifikasi teks berbasis Python. Dari percobaan yang telah dilakukan ternyata algoritma Naïve Bayes dapat digunakan untuk mengklasifikasi berita palsu. Berdasarkan eksperimen, penggunaan metode naive bayes untuk deteksi validitas berita dengan data uji media social Twitter dapat mencapai nilai akurasi dengan persentase terbaik yaitu $92 \%$ pada data ujicoba sebesar 309 artikel.
\end{abstract}

Kata kunci- Berita Palsu, Klasifikasi Dokumen, Machine Learning, Naïve Bayes, Natural Language Processing.

\section{PENDAHULUAN}

Berita palsu alias hoax banyak ditemui di internet. Masyarakat pun sering kali tertipu dan turut berperan dalam semakin meluasnya penyebaran berita palsu di berbagai media sosial. Berita palsu merupakan kumpulan kata atau kalimat yang mengandung informasi yang tidak benar.

Esther Irawati Setiawan, Teknik Informatika, Institut Sains dan Teknologi Terpadu Surabaya, Surabaya, Jawa Timur, Indonesia (e-mail: esther@istts.ac.id)

Sugiharto Johanes, Teknik Informatika, Institut Sains dan Teknologi Terpadu Surabaya, Surabaya, Jawa Timur, Indonesia

Arya Tandy Hermawan, Teknik Informatika, Institut Sains dan Teknologi Terpadu Surabaya, Surabaya, Jawa Timur, Indonesia (e-mail: arya@ stts.edu)

Yuni Yamasari, Teknik Informatika, Universitas Negeri Surabaya (email: yuniyamasari@unesa.ac.id)
Berita palsu biasanya berupaya untuk membohongi atau mengarahkan pembaca atau pendengarnya agar mendukung atau percaya dengan isi beritanya. Penyebar berita palsu umumnya mengetahui bahwa berita yang disebarkan tidak benar. Salah satu model pemberitaan palsu yang paling umum adalah menyebutkan suatu foto dari suatu kejadian sebagai kejadian lainnya dengan tujuan tertentu dari penyebarnya [1].

Berita palsu juga menjadi alat untuk mengarahkan opini public, yang dibaliknya ada tunggangan kepentingan sesorang atau komunitas tertentu. Selain itu, berita palsu yang kontroversial juga dapat dimanfaatkan penyebarnya untuk mendapatkan penghasilan dengan meningkatkan kunjungan ke situs yang dipasangi iklan. Padahal, berita palsu bisa menyesatkan dan menimbulkan kerugian bagi pihak yang menjadi korban. Dampak negatif yang ditimbulkan berupa kerugian moril maupun materiil, misalnya kehilangan reputasi, bahkan juga bisa memunculkan kebencian dari pembacanya hingga membahayakan korban.

Belakangan ini, penyebaran berita palsu banyak digunakan untuk tujuan politis. Ada pihak tertentu yang ingin menjatuhkan lawan politiknya, sehingga memanfaatkan berita palsu sebagai senjata. Pihak-pihak tersebut sengaja menggunakan media sosial untuk mempopulerkan isu negatif. Hal ini bertujuan untuk memenangkan persaingan politik sehingga terkadang antar kandidat berserta pendukung masing-masing melakukan hal-hal yang menyalahi etika demi memperoleh kemenangan.

Penyebaran berita palsu di media sosial dan aplikasi pesan telepon genggam sangat marak dan masif sehingga berdampak negatif bagi masyarakat. Efek negative yang ditimbulkan adalah rasa tidak aman, kekuatiran, kebingungan, dan kekerasan. Berita palsu dapat memperparah konflik suku, agama, ras antar golongan.

Dampak negatif berita palsu yang dipercaya oleh seseorang atau sebagian masyarakat dapat menyebabkan perpecahan dalam masyarakat, hingga pertikaian antar negara. Berita palsu dapat menyebabkan pertengkaran antar kelompok atau antar orang. Berita palsu sering mengandung hasutan dan juga ujaran kebencian yang mengganggu keharmonisan masyarakat.

Deteksi validitas berita dapat dilakukan dengan menggunakan pendekatan klasifikasi teks [2]. Metode Support Vector Machine dan C4.5 dapat digunakan untuk 


\section{JOURNAL OF INTELLIGENT SYSTEMS AND COMPUTATION}

klasifikasi validitas berita [3]. Berbagai pendekatan lainnya telah digunakan untuk klasifikasi berita palsu, salah satunya adalah Stance Classification [4]. Stance Classification telah menggunakan berbagai pendekatan, yaitu Hidden Markov Model [5], Ensemble Classification [6], dan Deep Learning [7][8][9].

Sosial media adalah tempat dimana masyarakat menyampaikan pendapatnya, dan berita palsu tersebar dengan cepat. Klasifikasi dan deteksi berita palsu telah dilakukan pada Twitter [10]. Penelitian ini melakukan deteksi validitas berita pada media sosial dengan pendekatan Naïve Bayes.

Makalah ini terbagi atas lima bab utama. Bab pertama menjelaskan mengenai pendahuluan dan latar belakang. Bab kedua membahas mengenai metodologi penelitian. Bagian ketiga berisi tentang hasil dan pembahasan. Bab terakhir memaparkan kesimpulan yang diperoleh setelah melakukan penelitian.

\section{METODOLOGI}

Metodologi pada penelitian deteksi berita palsu ini ditampilkan pada Gambar 1. Terdapat tiga tahapan utama yaitu praproses, pelatihan dan pengujian. Pada tahap praproses, data dari media sosial diolah agar dapat digunakan untuk pelatihan maupun pengujian. Tahap pelatihan mengolah data-data cuitan dengan metode klasifikasi Naïve bayes, dan tahap pengujian bertujuan untuk melakukan klasifikasi terhadap cuitan yang ada di media sosial, apakah termasuk berita palsu atau tidak.

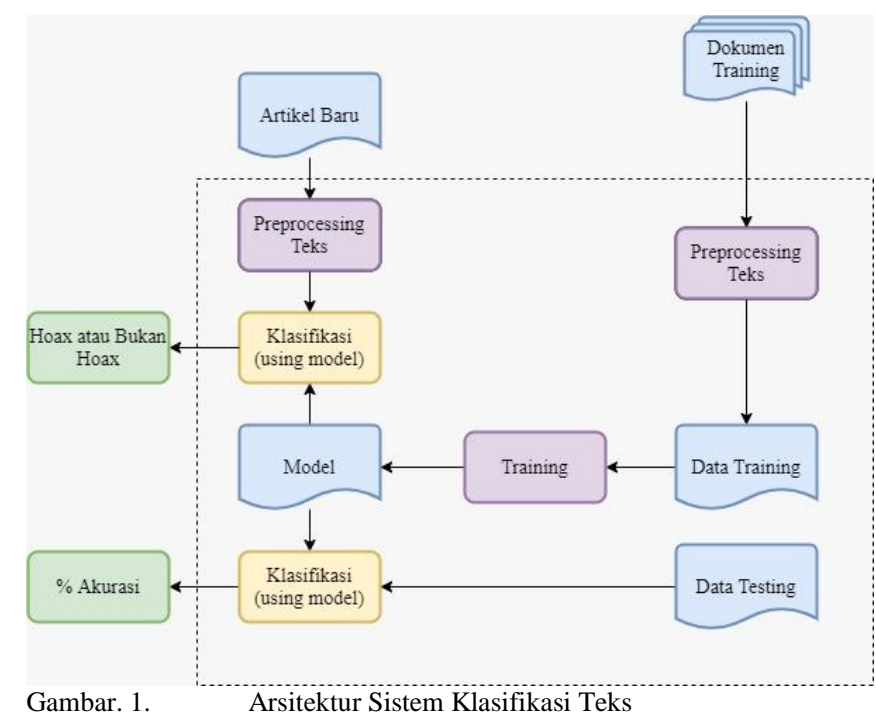

Pada Gambar 1 ditampilkan arsitektur sistem pada aplikasi ini. Arsitektur sistem ini menunjukkan bagian back-end atau klasifikasi dari aplikasi karena front-end dari sistem hanya menampilkan data yang diolah di back-end.

Dokumen training yang sudah dimiliki dan dilabeli secara manual akan disiapkan sebelum klasifikasi pada tahapan preprocessing teks. Setelah semua proses tersebut selesai akan didapatkan data training yang siap dilatih. Setelah dilatih kita akan mendapatkan model training yang dapat digunakan untuk mengklasifikasi artikel baru.

Sebelum melakukan klasifikasi dengan artikel baru, akan dicoba menggunakan data training yang sudah dimiliki.
Sebagian data training akan digunakan sebagai testing untuk mengetahui keakuratan dari klasifikasi. Jika akurasi yang didapatkan kurang tinggi, maka akan data training dioptimalkan kembali untuk mendapatkan akurasi yang tertinggi. Perbaikan yang dapat dilakukan adalah pemilihan data training yang lebih baik atau pemilihan penggunaan preprocessing teks yang berguna.

Jika model training sudah ada, maka dapat dilakukan pengklasifikasian menggunakan artikel baru. Proses awal dari artikel baru kurang lebih sama dengan data training. Artikel baru akan melewati proses preprocessing seperti data training. Lalu dengan menggunakan model klasifikasi yang ada akan dilakukan klasifikasi. Hasil dari klasifikasi akan muncul dengan probabilitas antara berita palsu atau bukan.

Alur kerja dalam sistem ini membutuhkan back-end untuk memberikan hasil klasifikasi kepada pengguna. User interface merupakan website berbasis PHP dimana pengguna dapat melakukan interaksi secara langsung sepeti komentar, login, atau melihat artikel-artikel yang sudah diklasifikasi. Sedangkan back-end dari website ini adalah program klasifikasi teks berbasis Python. Semua artikel yang akan diklasifikasi nantinya akan dikirim ke program Python lalu akan diterima kembali hasilnya untuk ditunjukan kepada pengguna.

Ketersediaan data training untuk deteksi validitas berita dalam Bahasa Indonesia belum ada untuk penelitian ini. Sehingga dalam penelitian ini perlu dilakukan pengumpulan data training yang sesuai agar dapat melakukan klasifikasi ke kategori yang tepat. Pengumpulan data berupa artikel berbahasa Indonesia.

\section{A. Praproses}

Preprocessing adalah pengolahan awal data text yang akan dibaca, sebelum dilanjutkan ke proses utama. Preprocessing meliputi stopword removal dan stemming. Stopword removal digunakan untuk membuang kata-kata penghubung dan stemming digunakan untuk mengembalikan kata menjadi kata dasar.

Preprocessing dilakukan terhadap data latih maupun data uji. Kemudian tahapan penghilangan stopword juga dilakukan untuk menghilangkan kata-kata yang terlalu umum pada koleksi dokumen yang dapat mengganggu performansi dan akurasi. Sedangkan tahapan stemming digunakan untuk mengembalikan kata ke bentuk dasarnya, karena varian katakata berimbuhan dalam Bahasa Indonesia yang cukup banyak. Berikut merupakan penjelasan lebih detail mengenai preprocessing yang dipakai dalam penelitian ini:

1. Stopwords Removal: dalam pengolahan Bahasa alami, stopword adalah kata-kata yang dihilangkan sebelum diproses algoritma klasifikasi. Daftar kata-kata ini umumnya diatur dalam stoplist. Stop word umumnya adalah kata yang yang mempunyai jumlah kemunculannya tinggi misalnya kata penghubung seperti "maka", "sehingga", "dan", dan sebagainya. Terdapat berbagai pendekatan dalam penentuan stop word, dan biasanya penentuan stopword sesuai koleksi dokumen yang akan diolah. Dengan penghilangan stopword, diharapkan pengolahan klasifikasi lebih cepat dengan menghilangkan kata-kata yang tidak penting dan tidak relevan untuk diolah.

2. Stemming merupakan metode yang penting untuk praproses teks yang mengambil kata dasar sebuah kata 


\section{JOURNAL OF INTELLIGENT SYSTEMS AND COMPUTATION}

dengan membuang awalan, sisipan dan akhirannya. Stemming berupaya menangani berbagai varian kata yang ada pada cuitan yang sebenarnya sama kata dasarnya. Penelitian ini menggunakan stemming metode Sastrawi, sedangkan untuk penghapusan awalan, sisipan, dan akhir menggunakan algoritma dari Nazief dan Adriani.

\section{B. Klasifikasi dengan Nä̈ve Bayes Classifier}

Naive bayes classifier adalah sebuah metode klasifikasi dengan teorema bayes sebagai dasarnya. Thomas Bayes, seorang ilmuan Inggris, mengusulkan metode pengklasifikasian dengan konsep probabilitas dan statistik yang memprediksi peluang di masa depan dari kejadian sebelumnya. Naive Bayes Classifier mengambil asumsi naïve yaitu setiap kondisi atau kejadian bersifat independen [11]. Untuk klasifikasi teks, Naïve Bayes dapat digunakan untuk penyederhanaan rumus berdasarkan Rumus 1 .

$$
V_{M A P}=\underset{v_{j} \in V}{\arg \max } \frac{P\left(a_{1}, a_{2} \ldots a_{n} \mid v_{j}\right) P\left(v_{j}\right)}{P\left(a_{1}, a_{2} \ldots a_{n}\right)}
$$

$\left(a_{1}, a_{2}, \ldots, a_{n}\right)$ merupakan bilangan konstan, sehingga dapat disederhanakan menjadi Rumus 2. $v_{j}$ adalah probabilitas setiap kalimat terhadap sekumpulan kalimat.

$$
V_{M A P}=\underset{v_{j} \in V}{\arg \max } P\left(a_{1}, a_{2} \ldots a_{n} \mid v_{j}\right) P\left(v_{j}\right)
$$

Naïve Bayes dapat digunakan untuk klasifikasi validitas berita pada data media sosial seperti penelitian [12] yang menggunakan Naïve Bayes untuk klasifikasi teks. Pada penelitian ini, setiap kata akan dihitung frekuensi kemunculannya dengan pendekatan Bag of Word. Kemudian dilanjutkan dengan tahapan klasifikasi menggunakan Naïve Bayes.

\section{HASIL DAN PEMBAHASAN}

\section{A. Aplikasi Web Deteksi Validitas Berita}

Pada bagian ini akan dijelaskan mengenai arsitektur aplikasi web yang telah dikembangkan dalam penelitian ini. Selain arsitekur umum, akan dijelaskan mengenai fitur-fitur yang ada beserta dan input-output yang dihasilkan dari penelitian ini. Gambar 2 menunjukkan artistektur umum dalam aplikasi web penelitian ini.

Pertama-tama pengguna melakukan login terlebih dahulu untuk dapat menggunakan website. Pengguna dapat melakukan register jika belum pernah membuat account sebelumnya. Setelah login, kemudian pengguna dapat melakukan klasifikasi teks secara manual.

Hal ini dilakukan dengan mengisi teks di tempat yang sudah disediakan. Setelah itu akan keluar hasil yang klasifikasi teks yang diharapkan. Kemudian jika pengguna ingin melakukan comment terhadap artikel-artikel yang sudah diklasifikasi, pengguna dapat pergi ke halaman berita untuk melihat semua berita yang ada. Pengguna dapat melihat artikel apa saja yang sudah diklasifikasi oleh sistem.

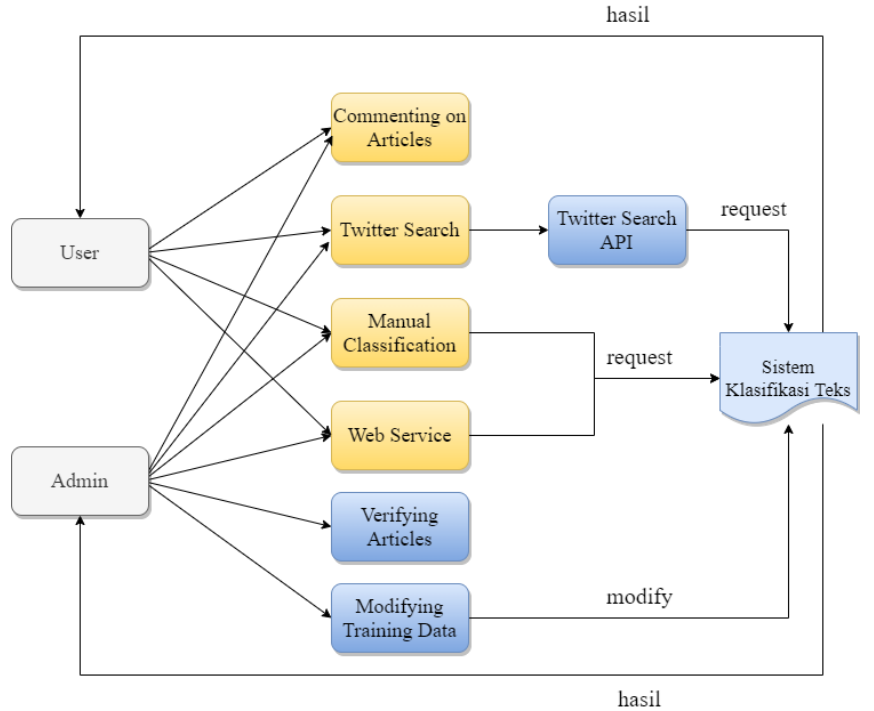

Gambar. 2. Arsitektur Aplikasi Web

Pengguna juga dapat melakukan search artikel-artikel yang ada di Twitter. Sistem akan melakukan request pada Twitter API ketika pengguna melakukan search query sesuai dengan keyword yang diisi. Kemudian akan ditampilkan semua hasil yang sesuai dengan keyword yang dicari beserta hasil klasifikasi yang sudah dihitung. Pengguna dapat membuka source dari berita yang sudah dicari. Output pada halaman ini akan juga menampilkan rekomendasi beritaberita yang sebenarnya. Rekomendasi berita-berita sebenarnya ini yaitu berupa dataset non-hoax yang sudah dikumpulkan.

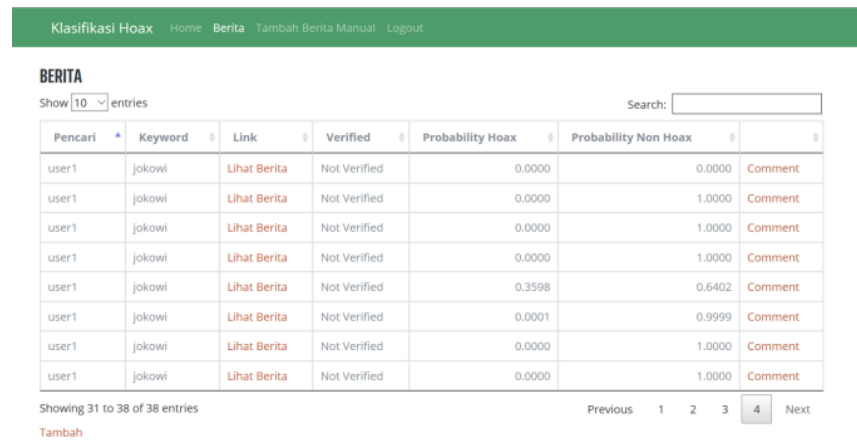

Gambar. 3. Tampilan Halaman Admin

Pada bagian dipaparkan fitur-fitur apa saja dari web yang dibuat pada penelitian ini. Fitur-fitur yang akan ada pada penelitian ini antara lain adalah sebagai berikut:

a. Login

Pengguna dapat melakukan pendaftaran untuk menjadi user di website ini. Walaupun begitu, pengguna lainnya tetap mampu untuk menggunakan website tanpa perlu login. Fungsi login disini hanyalah agar pengguna dapat turut serta dalam membantu berupa comment agar hasil-hasil klasifikasi yang salah dapat diperbaiki.

b. Search Article

Pengguna dapat mencari berita yang ada di Twitter lalu secara otomatis sistem akan mengklasifikasi seluruh berita yang sesuai dengan topik yang dicari. 


\section{JOURNAL OF INTELLIGENT SYSTEMS AND COMPUTATION}

c. Klasifikasi Berita

Pengguna mampu memasukkan teks berita ke dalam halaman yang sudah disediakan lalu sistem akan langsung memproses teks tersebut dan mengeluarkan hasil apakah berita tersebut palsu atau bukan.

d. Comment

Disini comment berfungsi sebagai pembantu klarifikasi berita yang sudah ada. Jadi misalnya jika ada berita palsu tetapi dinilai bukan palsu oleh sistem, maka pengguna dapat melakukan klarifikasi melalui comment dan admin akan dapat melakukan tindakan lanjutan.

e. Admin Page

Halaman admin berfungsi agar admin dapat melihat dan memodifikasi dataset berita palsu dan nonpalsu. Seorang admin juga dapat memoderasi comment yang ada di berita-berita, melakukan klasifikasi berita baru, dan mengganti hasil klasifikasi yang salah jika terdapat sumber yang dapat dipercaya. Tampilan halaman Admin dapat dilihat pada Gambar 3.

f. Fitur Service

Disediakan juga fitur service untuk dapat digunakan dalam aplikasi lain. Aplikasi lain dapat mengirim teks lewat URL yang sudah disediakan lalu mendapatkan kembalian berupa JSON yang berisi probabilitas teks yang sudah dikirim. Setelah user mengirim teks berita lewat url hoax/validitasberita/getclassification.php?text= akan mendapatkan kembalian berupa JSON yang berisi probabilitas hoax, non-hoax, dan kelasnya. Jika probabilitas hoax lebih tinggi berarti merupakan kelas hoax dan juga sebaliknya. User dapat menggunakan fitur ini dengan mengisi langsung teks berita lewat url dari website. Yang menjadi batasan adalah limit character url. Mengakibatkan tidak bisa mengirim teks berita yang terlalu panjang. Limit character tergantung pada browser yang digunakan oleh user.

Berikut merupakan fungsi detail beserta parameter dari web service yang disediakan:

1. URL: hoax/validitasberita/getclassification.php?text=

Merupakan metode akses dari web service yang sudah disediakan dari website ini. Pengguna dapat memasukkan teks yang ingin diketahui tepat sesudah URL tersebut.

2. probabilityHoax $=$ merupakan probabilitas hoax dari teks yang dikirimkan oleh pengguna.

3. probabilityNonHoax $=$ merupakan probabilitas hoax dari teks yang dikirimkan oleh pengguna.

4. kelas = merupakan kelas dari teks yang dikirimkan pengguna. Terdapat 2 kelas yaitu hoax atau non-hoax. Dikatakan hoax jika probabilityHoax lebih tinggi dari probabilityNonHoax. Begitu juga sebaliknya.

5. Contoh pengembalian dan format JSON yang akan diterima:

\{

"probabilityHoax":"0.745338",

"probabilityNonHoax":"0.254662",

"kelas":"hoax"

\}

\section{B. Pengujian Model}

Pada bagian ini akan dijelaskan uji coba dataset yang digunakan pada penelitian ini. Uji coba dataset berguna untuk mengetahui tingkat akurasi dari klasifikasi berita palsu. Terdapat beberapa scenario uji coba yang akan dilaporakan pada penelitian ini.

Pada skenario pertama, dilakukan uji coba dengan preprocessing stemming. Dataset training terdiri dari 603 artikel palsu dan 592 artikel non-palsu. Dalam uji coba dataset ini data digunakan adalah sebanyak 309 artikel, dengan rincian yaitu 152 berita palsu dan 157 non-palsu. Data uji coba sebanyak 309 ini sendiri diambil dari dataset dan tidak digunakan selama training, melainkan sebagai data data uji coba.

TABEL I

Confusion Matrix Data Uji Coba dengan Stemming

\begin{tabular}{|c|c|c|}
\hline $\mathrm{N}=309$ & Predicted Hoax & $\begin{array}{c}\text { Predicted Non- } \\
\text { Hoax }\end{array}$ \\
\hline $\begin{array}{l}\text { Actual } \\
\text { Hoax }\end{array}$ & 135 & 17 \\
\hline $\begin{array}{l}\text { Actual } \\
\text { Non-Hoax }\end{array}$ & 7 & 150 \\
\hline & 142 & 167 \\
\hline
\end{tabular}

Berdasarkan hasil uji coba pada tabel 1 didapatkan bahwa terdapat jawaban yang tidak sesuai. Namun untuk mengetahui persentase kesuksesan, dari data pada tabel confusion matrix tersebut akan dilakukan perhitungan akurasi, presisi, recall, dan F measure. Dari confusion matrix tersebut didapatkan True Positive, True Negative, False Positive, dan False Negative.

Sedangkan perhitungan akurasi, presisi dan recall, dan F1 dapat dilihat pada penjelasan selanjutnya.

$$
\begin{aligned}
& \text { True Positive }(T P)=135 \\
& \text { True Negative }(T N)=150 \\
& \text { False Positive }(F P)=17 \\
& \text { False Negative }(F N)=7 \\
& \text { Accuracy } \\
& =\frac{150+135}{150+135+17+7} \\
& =0.922330097 \\
& \text { Recall } \quad=\frac{150}{150+7} \\
& =0.955414013 \\
& \text { Precision } \quad=\frac{150}{150+17} \\
& =0.898203593 \\
& \text { F1 Measure } \quad=\frac{2 * 0.955414013 * 0.898203593}{0.955414013+0.898203593} \\
& =0.925925926
\end{aligned}
$$

Karena data uji coba berasal dari data training maka sudah diketahui kelas asli dari artikel-artikel uji coba. Dari sana akan dilakukan klasifikasi terhadap data uji coba. 
INSYST

Setelah uji coba selesai hasil klasifikasi akan disesuaikan dengan kelas asli dari artikel-artikel tersebut. Jika kelas hasil klasifikasi uji coba sama dengan kelas asli artikel maka klasifikasi terhadap artikel tersebut dinyatakan benar. Setelah dilakukan uji coba didapatkan hasil dari True Positive, True Negative, False Positive, dan False Negative. Untuk mendapatkan akurasi dapat dilakukan pembagian dari total TP+TN dengan total TP + TN + FP + FN . Dari uji coba ini akhirnya didapatkan hasil akurasi sebesar $92 \%$.

Skenario uji coba kedua adalah perbandingan tanpa menggunakan stemming. Seperti yang ditampikan pada tabel II, tanpa melakukan stemming diperoleh perbedaan hasil. Dapat diketahui bahwa uji coba tanpa menggunakan stemming memerlukan waktu yang lebih singkat namun akurasi yang diperoleh sebesar $84 \%$.

TABEL II

Confusion Matrix Data Uji Coba tanpa Stemming

\begin{tabular}{lcc}
\multicolumn{1}{c}{$\mathrm{N}=309$} & Predicted Hoax & \multicolumn{2}{c}{$\begin{array}{c}\text { Predicted Non- } \\
\text { Hoax }\end{array}$} \\
\hline $\begin{array}{l}\text { Actual } \\
\text { Hoax } \\
\text { Actual }\end{array}$ & 114 & 38 \\
Non-Hoax & 10 & 147 \\
\hline & 124 & 185 \\
\hline
\end{tabular}

Sedangkan scenario uji coba ketiga adalah penggunaan k-fold cross validation untuk mengetahui kehandalan sistem klasifikasi. Pada masing-masing fold yang diujicobakan adalah sebesar 120 artikel, yaitu 60 artikel hoax dan 60 artikel non-hoax. Tahap Preprocessing yang digunakan pada semua fold yaitu penghilangan stopwords saja. Semua fold tidak memakai preprocessing stemming.

Dataset tersebut diklasifikasikan menggunakan naïve bayes dengan pengujian 10-fold cross validation. Dapat dilihat pada Tabel bahwa nilai akurasi terbaik dihasilkan model fold-8 dengan nilai 93,33\%. Dan nilai akurasi terendah adalah $85 \%$ yang dihasilkan model fold-5. Rata-rata akurasi dari 10 -fold cross validation tersebut adalah sebesar $89 \%$. Hasil 10-fold cross validation tampak pada tabel III dan grafik akurasi setiap fold ditampilkan pada Gambar 4 .

TABEL III

10-fold Cross Validation

\begin{tabular}{|r|r|}
\hline \multicolumn{1}{|c|}{ No } & \multicolumn{1}{|l|}{ Accuracy } \\
\hline 1 & $86,66 \%$ \\
\hline 2 & $86,66 \%$ \\
\hline 3 & $90,00 \%$ \\
\hline 4 & $88,33 \%$ \\
\hline 5 & $85,00 \%$ \\
\hline 6 & $86,66 \%$ \\
\hline 7 & $91,66 \%$ \\
\hline 8 & $93,33 \%$ \\
\hline 9 & $90,83 \%$ \\
\hline 10 & $91,07 \%$ \\
\hline
\end{tabular}

Selain itu, dilakukan juga uji coba performa klasifikasi dengan spesifikasi perangkat keras Intel® Core i7-4710HQ @ 2.50GHz dan RAM 8 GB. Untuk pengolahan 1.561 artikel berita dari sosial media Twitter, dibutuhkan waktu selama 2 menit sampai proses training selesai seperti yang ditampilkan pada Gambar 5.

\section{KESIMPULAN}

Berdasarkan proses penelitian, serta hasil dari uji coba yang telah dilakukan, terdapat beberapa kesimpulan. Kesimpulan pertama dari pengembangan penelitian ini adalah yang pertama algoritma Naïve Bayes dapat digunakan untuk mengklasifikasi berita hoax. Klasifikasi validitas berita pada media social dengan metode naive bayes menghasilkan akurasi yang baik pada data dari Twitter, dan menghasilkan nilai akurasi dengan persentase tertinggi $92 \%$ untuk data ujicoba sebesar 309 artikel.

Selain itu, preprocessing sebelum proses klasifikasi artikel berita palsu pada media social ternyata dapat mempengaruhi hasil akurasi saat uji coba. Kemudian nilai akurasi dari sistem klasifikasi diharapkan dapat meningkat dengan penambahan data training. Untuk saran penelitian selanjutnya, dapat dilakukan ensemble classification untuk deteksi validitas berita.

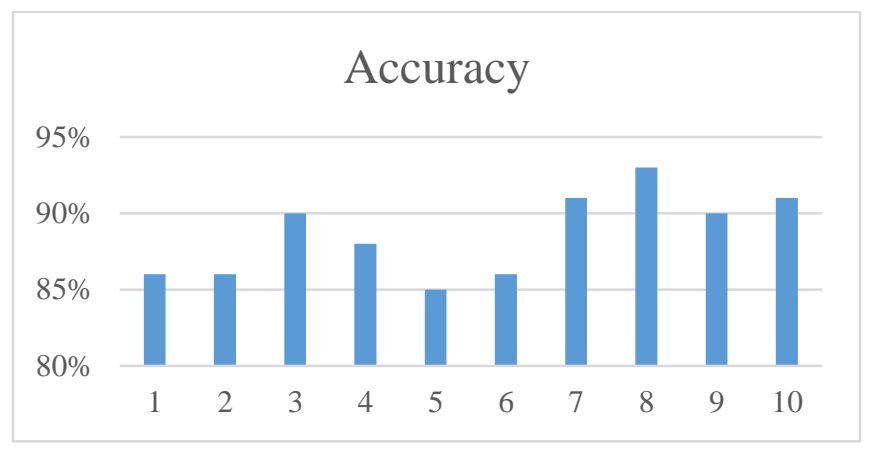

Gambar. 4. Grafik hasil 10-fold Cross Validation

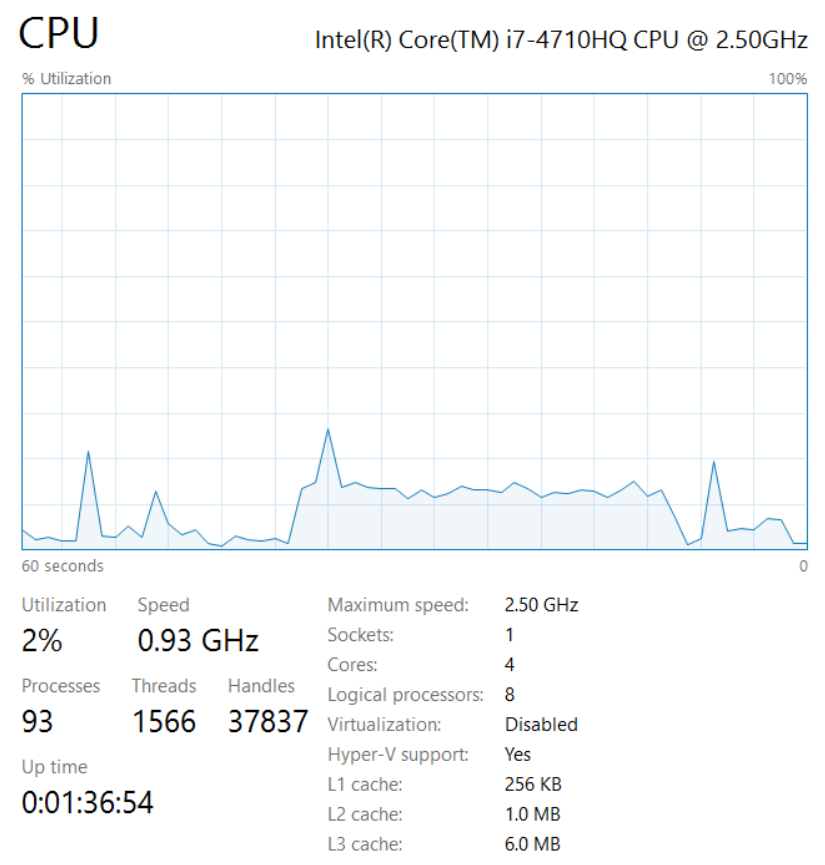

Gambar. 5. Penggunaan CPU saat Training

\section{DAFTAR PUSTAKA}

[1] E. Lararenjana, "Mengenal Arti Hoax Atau Berita Bohong, Ketahui Jenis dan Ciri-Cirinya," May 13, 2020.

https://www.merdeka.com/jatim/mengenal-arti-hoax-atau-beritabohong-dan-cara-tepat-menyikapinya-kln.html 
[2] E. Davis, J. Adams, and S. Cohen, "Classifying articles as fake or real," Language and Statistics course project, 2007.

[3] E. Rasywir and A. Purwarianti, "Eksperimen pada sistem klasifikasi berita hoax berbahasa Indonesia berbasis pembelajaran mesin," Jurnal Cybermatika, vol. 3, no. 2, 2016.

[4] A. Hanselowski et al., "A retrospective analysis of the fake news challenge stance detection task," arXiv preprint arXiv:1806.05180, 2018.

[5] A. E. Lillie and E. R. Middelboe, "Fake news detection using stance classification: A survey," arXiv preprint arXiv:1907.00181, 2019.

[6] J. Thorne, M. Chen, G. Myrianthous, J. Pu, X. Wang, and A. Vlachos, "Fake news stance detection using stacked ensemble of classifiers," in Proceedings of the 2017 EMNLP Workshop: Natural Language Processing meets Journalism, 2017, pp. 80-83.

[7] E. Lim, E. I. Setiawan, and J. Santoso, "Stance Classification Post Kesehatan di Media Sosial Dengan FastText Embedding dan Deep Learning," Journal of Intelligent System and Computation, vol. 1, no. 2, pp. 65-73, 2019.

[8] E. I. Setiawan et al., "Analisis Pendapat Masyarakat terhadap Berita Kesehatan Indonesia menggunakan Pemodelan Kalimat berbasis LSTM," Jurnal Nasional Teknik Elektro dan Teknologi Informasi, vol. 9, no. 1, pp. 8-17, 2020.

[9] G. Rajendran, B. Chitturi, and P. Poornachandran, "Stance-in-depth deep neural approach to stance classification," Procedia computer science, vol. 132, pp. 1646-1653, 2018.

[10] A. Addawood, J. Schneider, and M. Bashir, "Stance classification of twitter debates: The encryption debate as a use case," in Proceedings of the 8th International Conference on Social Media \& Society, 2017, pp. $1-10$.

[11] A. A. Muin and others, "Metode Naive Bayes Untuk Prediksi Kelulusan (Studi Kasus: Data Mahasiswa Baru Perguruan Tinggi)," Jurnal Ilmiah Ilmu Komputer Fakultas Ilmu Komputer Universitas Al Asyariah Mandar, vol. 2, no. 1, pp. 22-26, 2016.

[12] D. N. Chandra, G. Indrawan, and I. N. Sukaraja, "Klasifikasi Berita Lokal Radar Malang Menggunakan Metode Naïve Bayes Dengan Fitur N-Gram," Jurnal Ilmiah Teknologi Informasi Asia, vol. 10, no. 1, pp. 11-19, 2016. 